\title{
Nijmegen breakage syndrome
}

INSERM

\section{Source}

INSERM. (1999). Orphanet: an online rare disease and orphan drug data base. Nijmegen breakage syndrome. ORPHA:647

Nijmegen breakage syndrome is a rare genetic disease presenting at birth with microcephaly, dysmorphic facial features, becoming more noticeable with age, growth delay, and later-onset complications such as malignancies and infections. 